Time \& Society

0 (0) $1-24$

\title{
Time and temporality in online corporate pictorials
}

\section{Hans Rämö}

@SAGE

Stockholm Business School, Stockholm University,

Sweden

\begin{abstract}
Many different social contexts are embedded in, and mediated by, visual practices, so too in corporate communication. The specific aim of this paper is to use the concept of scopic regimes as a means of understanding pictorial representations of time and temporality in online corporate communication. It is argued in this paper that the temporal reference has changed direction, from pointing backward to forward. What has been a matter of predominantly portraying important corporate achievements to posterity has increasingly become a matter of appearing for impatient online viewers today as responsible for the future. Three illustrative examples of time and temporality in online corporate pictorials are included and discussed, representing movement, moment, and the allegory of time.
\end{abstract}

\section{Keywords}

Corporate communication, pictorials, responsibility, scopic regimes, temporality, time

\section{Setting the stage}

For most people, seeing is the dominant sense, what we see and how we comprehend the visual information is influenced by our expectations and the feelings these evoke in us. The focus of the interest in a media-saturated culture is in the extent to, as well as the manner, in which different forms of social and cultural practices are structured or shaped by images and how these images are seen and perceived. The perception of time and temporality

\section{Corresponding author:}

Hans Rämö, Stockholm Business School, Stockholm University, S-106 91 Stockholm, Sweden.

Email: hra@sbs.su.se 
(past, present, future) is also affected by what is seen, and how it is seen is reflected through personal experiences and how these relate to what is looked at. The recent proliferation of online pictorials has particularly influenced the perception of time and temporality, not only in terms of increased speed and quantity but also in terms of recollection of time. By the term pictorial is here meant photographs of some thing or some situation with attached captions, which is intended to illustrate and emphasize whatever message is to be conveyed. Some of these pictorials have recurrent time-related motifs, particularly when included in themes and messages that are forward-looking and visionary. However, to separate and demarcate forms and sources of media from one another is hardly possible as all "media are mixed in different ways" and there is always a "problematic gap" between image and text (Elleström, 2010: 24; McLuhan, 1964/1994; Mitchell, 1994: 89). One example of such multimodality is corporate communications that were traditionally confined to print and broadcast but are increasingly integrated into dynamic online settings, with text and figures, charts and tables, as well as images and video clips.

Dynamic online and real-time information frequently include pictorial depictions that carry the restless viewer and observer forward. For instance, over the past 10 to 15 years, CCTV has become ubiquitous as a (panoptical) source of real-time surveillance information - and not just only on city streets but also in factories, offices, and warehouses (Norris, 2012). The focus on the instantaneous is also evident in Instagram's social networking service spreading the (rhopographic) visualizations of "now." The spreading of online pictorial information has therefore influenced our approach to accessibility, but also the quest for what is new right now.

The "lure of the new" involves the mesmerizing "deconstruction of the old" (De Cock and Rehn, 2006: 123), and with "neophilia, the new is something to be loved, worshipped, and adored for its own sake" (Rhodes and Pullen, 2010: 2). The "obsession with the present-mindedness" (Innis, 1951: 76) also challenges the efforts to preserve digital narratives (Pietrzyk, 2012). Innis (1951) described the structural capacities of media to be biased towards either time or space where time-biased information is characterized as traditional, ceremonial and geographically confined (e.g., stone carvings) and space-biased information is less durable (e.g., paper) but easy to transport and "secular, present-minded" (Babe, 2004: 284, quoted in Pietrzyk, 2012: 128). Following from this, means that pictorial online information is space-biased and particularly ephemeral in terms of duration.

Availability at an instant has in many ways become the measure. Harvey (1990) first articulated the concept of time-space compression, which occurs as a result of technological innovations that condense or elide spatial and 
temporal distances. Virilio's (1991) treatise on dromology and time compression indicates that higher speed always strikes slower speed, which leads to a "society intensely present here and there at once-in other words telepresent to the whole world'(Bartram, 2004: 293; Virilio, 1997: 25). Bartram (2004), using Virilio's concept of dromology, finds therefore that time compression creates new and detrimental forms of occulacentrism (privileging of vision) as it undermines time for deliberation. Similarly, authors such as Massey (1994), Nowotny (1994), Castells (1996), and Urry (2000) have discussed how a temporal regime characterized by compressed and accelerated time has affected late modern societies. Urry (2000), for instance, uses the concept of instantaneous time to capture the new time regime where temporal separation of cause and effect is replaced by fragmented presence of "nows." More recently, and perhaps more trivially, media theorist Douglas Rushkoff (2013: 7,8) says that the "present shock"-playing on the title of Alvin Toffler's 1970 "future shock"-is a real-time, always-on existence without past or a future, origins or goals; to living in a world where everything is happening now. The constant flow of pictorial online corporate communications is certainly an expression of such desire for the immediate.

Various forms of dynamic online depictions affect the perception of time and temporality. When "all" information is increasingly expected to be available at the time, also means that information related to temporal change and serial order (i.e., past, present, future) "should be" immediately available; what is seen now is what counts, and what is seen are increasingly pictorials passing by. There is of course a fascination with "seeing" what is happening "right now," but it is susceptible to errors and corruption. This applies, of course, to any information source. However, the difference is that the increasing focus on ephemeral depictions reduces the ability to put it into context and to evaluate afterwards. Pictorials of currently unfolding events can have roots going back decades, and the full story is not available without closer involvement.

Pictorials play an increasingly powerful role in how fluid and fast-moving online corporate communication is perceived by internal and external audiences to provide attractive and supposedly convincing presentations. Consequently, the continuous flux of opinionated pictorials affects the perception of, for example, the way corporations communicate. Nowadays, corporations act and react with regular online updates about their performance rather than just making quarterly disclosures, and this communication is increasingly image based (Argenti, 2006; Goodman and Hirsh, 2010). Not only a commonplace observation - that the flow of online pictorials is constantly increasing - but also that this flow of corporate pictorials affects the understanding of the past, the present, and the future 
(i.e., temporality). The increase in information that is instantaneously available online creates a demand for immediacy of content, with signs of what is to come rather than what has been.

There has been a shift of focus in corporate communications from predominantly printed material of the past (years' achievement) to online pictorials helping to provide instantaneous but short-lived promises of the future. The proliferation of online pictorials in corporate communication de-emphasizes the way things have been-say, the past year's performance-and instead exposes the possibilities that lies within each present moment (looking now), and above all future potentials (looking forward). Thus, the transience of online information disrupts the sense of continuity and trustworthiness that comes from documenting past achievements (cf. the German concept of Musealiserung in Böhne, 2005, 2007; Lübbe, 1990; Pazzini, 1989). Instead, optimistic overtones of the present future "imagined, planned, projected, and produced in and for the present" will soon be overridden by new promises for the future (Adam and Groves, 2007: 28; cf. Luhmann, 1976: 142). Particularly, online corporate accounting reporting has led to a proliferation of optimistic and forward-looking pictorials, not least in sustainability communication. Recently in corporate accounting, studies of rhetoric and photographs in accounting and reporting materials have been addressed by, for example, Davison (2007a, 2007b, 2009a, 2009b, 2014). Breitbarth et al. (2010) and Rämö (2011) have studied the use of photographs in sustainability reporting but without specifically focusing on the temporal aspects. Visual aspects of organizations have also been studied by, for example, Linstead and Höpfl (2000), Ray and Smith (2012), Strati (1997), Styhre (2009, 2010), to mention only a few (for an introductory overview, see also the International Network for Visual Studies in Organization: http://in-visio.org/) Nonetheless, Bell and Davison (2013) and Meyer et al. (2013) have highlighted the need for even more research into the visual dimension of organizations - and studies of temporal aspects of visuals are notably absent.

How the visual is socialized in visual culture, and particularly what this mean for the understanding of time and temporality, might seem to be a rather redundant statement. The focus on the present, and present-mindedness that treats history as representative of current concerns, is hardly a new finding. But a closer inspection unfolds a shift in how temporality is presented in image-rich corporate communications; from backward to forward orientation. It is therefore argued in this paper that what used to be a matter of predominantly portraying important corporate achievements to posterity has increasingly become a matter of appearing for online viewers today as responsible for the future. There is a need, therefore, for greater attention to the temporal underpinning of online corporate 
communications, for example, when persuasive pictorials about the future are presented to today's audiences.

Consequently, by focusing on the increasingly pictorial online content in corporate communication, the specific aim of this paper is to use the concept of scopic regimes as a means of studying how online pictorials shape and affect the understanding of time and temporal relations.

How, then, to study this large and ever-expanding body of visual corporate communication? Recently, it has become rather common to tackle historical questions of visual culture in terms of "scopic regimes." The term was first introduced by the French film critic Christian Metz and is used in opposition to the notion that "vision" is universal (Metz, 1981; see also Feldman, 1997, 2005; Jay, 1988, 1993). For Jay (1993: 69), "the vigorous privileging of vision" accompanied by technical advances marked the dawning of the modern era. This ocularcentrism, as a tendency towards visual metaphors, models, concepts, and priorities within cultural, scientific, and political discourse, is still a dominating form of creating and directing meaning, albeit in interaction with other parts of the cognitive system.

By foregrounding the notion of scopic regime emphasizes that ways of seeing are not natural but constructed and contextual. Scopic regimes thus become a matter of framing the visual and creating visible and invisible regimes at which the socialization of vision becomes important. What message the scopic regime is foregrounding is further intensified by the interaction between image and text in, for example, corporate online pictorials. This socialization is a network of cultural meanings generated from various discourses that shape the social practices of vision. It is thus acknowledged that visuality is deeply implicated in contemporary culture and society, which also has consequences for the understanding of time and temporality.

The proliferation of pictorials made possible by the development of online channels has increased the importance attributed to the value of visibility in contemporary culture. Feldman (2005: 224), for example, argues that scopic regimes "prescribe modes of seeing and object visibility and that proscribe or render untenable other modes and objects of perception." Gregory (2003: 224) says in a similar way that the idea of a systematic structuring of the visual field produces a "constructed visibility that allows particular objects to be seen in determinate ways." From this follow that some aspects stand out and catch the attention while others remain hidden or less visible. In terms of online pictorials, it does not only means that temporal references are discernible but also that the online format itself plays an important role in establishing temporal relationships and recollection.

Therefore, in this study of online corporate communication, scopic regimes are understood as a repertoire of readily recognizable cues at 
which some parts have salient temporal features while other elements are deemphasized. Although ways of seeing are often paradoxical and conflicted, scopic regimes are not in singular but overlapping and are to be understood as a heuristic concept. Scopic regimes embody different forms of visuality that permeate cultural and social groups' ways of seeing.

The presentation is arranged as follows: next comes a section on seeing and visualizing time. Then, three examples of recurrent visual motifs in contemporary corporate communications are presented. After that comes a discussion of the scopic regime implications of online corporate pictorials. Finally, concluding remarks are drawn in the last section.

\section{On seeing and visualizing time}

Can a painting or a photograph represent movement and the passage of time? Various visual depictions in the Western world and elsewhere have been used to represent time, particularly the flight of time and the perishableness of life and earthly joys. The horrifying image of Kronos (Saturn in Latin) devouring his children, the reaper with the sickle of time representing the inevitable harvest of human time, and the hourglass measuring the passage of time - all alludes to time long before the advent of the mechanical clock. Many depictions of time and temporality are also organized spatially. Time is traveling circuitously around the face of a clock, calendars are arranged as tables, and time-lines represent time as flowing from one direction to another. The notions of time and temporality are thus frequently understood as an extent or stretch of continued existence.

The representation of time using space is a matter of visual and conversational convenience with a long history. In 1766, Gotthold Ephraim Lessing, in Laokoon oder Über die Grenzen der Malerei und Poesie, proposed a well-known characterization of poetry as being extended in time and painting extended in space - an ideological assertion that has been disputed by, among others, Mitchell (1984) and Elleström (2010). Even before, Ernst Gombrich, in his essay Moment and Movement in Art (1964) emphatically rejected the very idea of a static image representing only an instant of time. Instead, static images can represent events covering a period of time and not only an instantaneous state of affairs. Muybridge's famous demonstration in 1887 with a number of successive photographs of galloping horses is therefore simply a misleading series of snapshots. Points in time (punctum temporis) are not unique incidents but parts of a duration with indistinct demarcations that have never existed instantaneously. Already, Aristotle and Augustine construe the indivisible moments as durationless. Still, as noted by Bergson (1911/2007: 322-323), we "take snapshots, as it were, of the passing reality...the mechanisms of our ordinary knowledge is of a 
cinematographical kind." Barthes (1981: 15) describes in a similar way cameras as "clocks for seeing" something that do not longer exist. With the exactitude of today's timekeepers, the attractiveness of measuring and looking at time as points is more pronounced than ever. Yet at the same time, cultural conventions prescribe how time and temporality can be represented also in pictures. Indeed, the ability to see is central to many but also visually impaired persons are able to understand of time-spaces, as demonstrated by, for example, Schillmeier (2008).

Pictorial representations rely on a tripartite relation between the original object, the depiction of the object, and the observer - a relation that is largely culturally imprinted. By perceiving objects and perceiving depictions that have something in common triggers recognition capacities. Even some features that cannot be depicted per se, such as the mental state of sadness, are triggered by a sadness-recognition capacity when pictures of sad faces are seen (Currie, 1995; Le Poidevin, 2007). The various forms of pictorial culture that is surrounding us are not only shaping the experience of time and temporality but also structuring and augmenting the relation to time and temporality.

Mimetic visualizations attract attention, deceive the eyes and minds alike, imitate and resemble what is desirable about the original, replace lesser qualities, and animate meaning. Verbal images, also in written form, such as figures of speech, similes, and metaphors, are generating mental imagery, whereas visual images are more immediate imitations (mimesis) of things in the physical world. These forms of images and imitations - written and pictorial as well as mental and physical-are simultaneously performing both aesthetic and mnemonic functions; and they also have temporal implications. The mental perception of visual images brings together what has happened, happens now, and possibly what will happen. The immediateness of visual perception precedes thinking in words, and the metaphorical mind precedes analytical consciousness (cf. Mignolo, 2000).

Mimesis is however an "extremely broad and theoretically elusive term that encompasses a range of possibilities" (Kelly, 1998: 233). Taussig (1993: xiii), having a biologically centered model, describes mimesis as "the nature that culture uses to create second nature, the faculty to copy, imitate, make models, explore difference, yield into and become Other." Still, mimetic imitation, representation, and mimicry have since the days of Plato and Aristotle been contrasted with diegesis, which instead of mimetically showing is telling the story by a narrator; for instance a story depicted on screen - as opposed to the original event that the screen narrative is about. According to Metz (1974/1991), diegesis includes not only the narration itself but also the fictional time dimension implied by the narrative. Seeing is thus much more than just observing and perceiving the outside 
world - a particular pictorial often represents something further. This becomes apparent also in the difference between "iconography" as the study of subject matter in the visual arts and "iconology" as an attempt to analyze the significance of that subject matter within the culture that produced it (Panofsky, 1955), as well as in the difference between the denotative obvious and representational meaning of a sign to its connotative socio-cultural and emotional associations.

The difference between instrumental and symbolic influence evokes a difference between what is expressed and how it is expressed in pictorials. Barthes (1961/1977), for instance, differentiates between levels of connotation, from the perceptual connotation that identifies the object depicted, via the cognitive connotation that recognizes aspects such as signs in the background and clothing of the depicted individuals, to the ideological connotation that introduces reasons or values into the reading of the image. Barthes (1961/1977) also points out that the rhetorical power of visual depictions is intensified when it is "anchored" by a text (Barthes, 1961/ 1977; Rosteck, 1994: 43).

For a long time, both rhetoric in words and visual rhetoric, for example in pictures, were understood mainly as linguistic embellishment and visual ornamentation. Particularly, pictures have frequently been both neglected and disdained in academic circles for their lack of rigor and for their potentially deceptive nature. Indeed, studies of visual rhetoric are still viewed by many with skepticisms and distrust. Boorstin (1961; see also Alvesson, 1990) was early in warning that the proliferation of highly visual pseudo-events can have a damaging effect on democracy. Similarly, Mitchell (1994) and Lucaites and Hariman (2001) note that visual rhetoric, for example in photographs, has commonly been thought to be out of control. Recently, however, such "iconoscepticism" (cf. Addison, 2003) have shown signs of giving way to a more open interest in visual rhetoric, particularly among social scientists exploring our expanding and dynamic visual and pictorial culture (not least in anthropology). In 1994, Mitchell argued for a critical "pictorial turn" (after the linguistic ditto), in the humanities, whereas Marcum (2002: 189) says that the "new reality is not just a visual culture - it is a visual ecology" (see also Curtis, 2010; Marcum, 2002; Mitchell, 1986, 1994).

One of the major trends in contemporary communication is the development of pictorial genres to carry information that cannot be carried easily by written media alone. Consequently, authors such as Schnettler and Raab (2009) and Seward Barry (1997) argue for the need of visual intelligence, which implies not only the skilled use of visual reasoning to read and to communicate but also an understanding of how the dynamic elements that compose meaning in images can be manipulative and political - an assertion that is valid particularly in online environments. 
One possible reason for the hesitation to study visual rhetoric is that pictorials carry multiple signifiers for various combinations of senders and receivers in different social and cultural settings. Pictorial representations are contingent upon how they are situated and interpreted (Pink, 2006). Still, the use and interpretation of codes and standards in contemporary life are becoming increasingly uniform across cultures - and the expansion of online communication has contributed to this, not least in the business community.

The growing online circulation of pictorials has particularly affected corporate communication, but the use of pictures and photographs in corporate reporting is nothing new. Already in the late 19th century, railway accounting statements in Britain were normally reproduced in one or more of the widely circulated periodicals and most companies printed the accounting statements and mailed them to shareholders (Edwards, 1989). Still, regulatory requirements in the 19th-century Britain and elsewhere varied according to the class or size of company (Parker, 1990). Preston et al. (1996: 113) find that in 1959, a graphic designer produced an annual report for Litton Industries, and this 'report has been referred to as the first 'concept' or 'modern' annual report" (Smithsonian Institution, 1988). But even before, the work of artists, photographers, and graphic designers was typically used in a documentary style, for example, when Hupp Motor Car featured its latest model car on the cover of its 1938 annual report (Preston et al., 1996). Arranged group photographs and portraiture of managers and executives have also been common in annual reports. McKinstry (1996) in a study of the British fashion retailer Burton PLC finds that design had a subordinate role until the 1970s when the graphic design of the annual report was used increasingly to embellish the financial information. Consequently, in the 1960s and 1970s, graphically designed annual reports with more than just documentary merits about previous year's financial account started to spread, and since then pictorials in corporate reporting and communication have become ubiquitous in print and online.

Directing one's attention towards something or someone is of course already a form of focus or perspective at which other aspects remain in the shadow or are omitted altogether. But the question can be further nuanced - are there particular aspects or elements that dominate in a certain area (foregrounding), directing attention away from other aspects (backgrounding)? The concept of scopic regimes could be a way of dealing with these issues. More specifically, when online corporate communication is imbued with pictorials, how can it influence our view of the past, the present, and the future; and what effect has the online format of representation? 


\section{Mise en Scène-Pictorial motifs with temporal dimensions}

Given the paucity of research in this area, an exploratory approach is appropriate at which pictorials from official corporate websites are used to illustrate the description. The aim here is only to give some illustrative examples of time and temporality in online corporate pictorials. The exact number of a certain depiction will certainly vary randomly from year to year depending on that year's theme - which is very much in the hands of the designers of the report. It is argued, however, that some basic pictorial themes and motifs are recurrent from year to year, and that many of these include temporal dimensions.

What, then, are the appropriate categories in a study of time orientations in online pictorials? To inform, to persuade, and to promote are general topics in business-related communications. Views suggested by Yates and Orlikowski $(1992,2002,2007)$ assert that genres of organizational communication can be characterized by having similarities in substance (general topics and specific themes) and forms, which refers to the observable features of structure, language, medium, or symbol. While Yates and Orlikowski's elaborations of genres in organizational communication - and many others using their ideas - have a focus on oral and written communication, this study transfers the reasoning to the pictorial field. As genres cannot be precisely defined, they are generally manifested to convey conventionalized features of situated linguistic and/or pictorial categories. Yates and Orlikowski $(2002: 14,15)$ identify "genres by their socially recognized purpose and by their common characteristics of form." One general pictorial genre distinction relates to the purpose of the genre (e.g., to inform or entertain). From this follow then a group of recurrent pictorial themes, for instance, cultural, moral, political, professional, and social. Over time, some of these recurrent pictorial themes can be identified by their use of familiar and formulaic motifs in a particular cultural context-nevertheless without being indisputable and unambiguous. By focusing more specifically on the context of online corporate communication implies that pictorials with formulaic motifs are giving immediate and accessible cues in formal presentations, while at the same time being fleeting and possibly deceptive.

Time and temporality in photographs can be depicted in many ways-but three frequent thematic motifs are in focus in this study. Perhaps the most visible example is action shots of movement, sometimes blurred, trying to give the impression of unfolding action and change (cf. Kress and van Leeuwen, 2006; Moya Guijarro and Pinar Sanz, 2008: 1606). Another example is when documentary-oriented photographs of decisive moments connote situations where something important happens, 
for example, when decisions are discussed and made (cf. Cartier-Bresson, 1952, see also e.g., Lester, 1991; Perlmutter, 1997). A third example is the allegory of time when the content of the immediate object is imposed by attributes of time and temporality. When presented as pictorials, the temporal dimensions of captured movements, decisive moments, or the allegory of time are further accentuated. Presented only as photographs might have been seen as just another example of visual embellishment, but with the attached captions, the messages have temporal dimensions. The imagery enhances the written text and vice versa, which makes the pictorial message immediate.

These three more or less arranged recurring pictorial motifs - captured movements, decisive moments, and allegory of time - are found throughout much of the online corporate communication and can be further illustrated with the following examples.

\section{Captured movements motif}

Pictures that apparently were taken in haste or at the right moment and showing movement sometimes with blurred elements - for example, dynamics and action when something action packed is going on. The scooterist, in picture 1 (Appendix 1), is in full control and enjoying what he is doing. The new electric scooter signals technological progress as an efficient way to get through the traffic jam and is thus far from the noisy and polluting petroleum-driven vehicle from the past. The caption from 2012 saying: On sale from 2014-The new electric scooter from BMW is furthering the prospect of progress and a promise of a better future. What was historically a motif in battlefield paintings exhibiting a dramatic sweep of the action is frequently found in later depictions of movement and dynamism.

\section{Decisive moments motif}

A leader talks to colleagues about an important upcoming decision or ongoing decision making-presented as determination at a decisive moment in the same way as in historical portraits of the leader pointing forward or signing a contract. The fit and disciplined contemporary leader in picture 2 (Appendix 1), with the relaxed outfit while talking to the more senior chairman, who has been hanging off his jacket but kept his tie on. Both being far from the strict and overweight posturing directors in the olden days. In addition, a forward-looking and promising preamble above the picture says (in Swedish, excluded here): The connected society takes shape. The pictorial connotes progress and advancement. 


\section{Allegory of time motif}

A representation that contains culturally acquired symbolic elements, providing shared sets of reference points with temporal and metaphorical meanings. Traditionally a motif represented in still-life paintings of the transience of life but also in delicate (or melancholic) portraits of youth and old age. This motif may be constructed as the example in picture 3 (Appendix 1), depicting a child holding an inflatable globe in a background of an ancient forest. The wholesome and seemingly happy child who in trying to play at an arranged and supervised situation in a place that seems to be too organized and filled with over-explicit symbolic meanings. The pictorial time horizon is furthered by the caption: Sustainable for the future, and by the fact that the sender is bank wishing to symbolize its stability over time.

Not surprisingly, the above pictorials are meant to emphasize Our (the Corporation's) goodwill, Our integrity, and Our commitment to the future, and to deemphasize the problems with Our operations. Such pictorials fill in and create idealized images of progress which is not always corresponding to the actual behavior of the corporations - although without at all discrediting the intentions of the corporations in the above examples. The pictorials are not only depicting a series of movement and occurrences in time but also having perceivable expressions promising progress to be made over time. What time regimes are then inherent in these pictorial presentations?

\section{Discussion}

In its simplest form, photographs are documents that remind of what has happened, and something that no longer exists. Photographs document and confirm the existence and passing of an event. Eventually describing a journey into the past, and to see something on a photograph that has happened becomes an imprint of the past, which do not age at the same pace as those depicted. Time makes a turn back, and what is seen today are portrayals and memories of what some considered worth preserving some point back in time. Whether these images were more or less edited photographs or pictorials containing text, they were nevertheless objects, as plates, negatives, or paper. Although not all of the documents from a company were to be preserved for future generations, it was still arduous to produce the material, which to some extend affected the output and the idea behind the publication. For the past decades, pictorials in corporate reports traditionally included portraits of the CEO, the board, and of recent products and buildings. Thus, documenting to the afterworld and preserving 
documents of what was (then) happening of importance. Portrayals of all form-whether carved in stone, painted in stucco or canvas, or caught on camera - tends to be more static representations of a presence, exposed, or mounted and framed for display in defiance of time. Nowadays, however, with the use of online communication, the visual culture has expanded beyond the traditional parameters of what can be produced by artists, artisans, and designers. It is not only easier, faster, and cheaper to produce and communicate online material, but the amount, availability, and the transitory nature also mean that much information disappear as new information replaces it. The quest for the easily accessible and visible means that expositions and complex ideas give way to simplifications, which preferably are presented in pictorial as opposed to purely verbal form. Historical intricacy can be downplayed and replaced with more selling pictorials. In corporate communications, the message should not only be informative but also to be persuasive and encouraging, which is certainly achieved with image-rich content. The image-rich content is increasingly pervasive but not necessarily lasting beyond the moment. Unfortunately, so too are many of the recurring corporate promises of responsibility for the future. New ones will soon replace today's messages of improvement, and so it goes on with short intervals. Therefore, what used to be pictorial documentation of yesterday's achievements in a corporation is increasingly being replaced by cursory pictorial promises of tomorrow. Statements of accounts with some pictorial features have to make way for more pictorial displays of commitment. Pictorial documentation supporting statements of accounts nowadays face competition from pictorial commitments superseding the specifics of the statements itself - in arrangements that are more immediately attractive for the restless viewer who rarely has time to dive into the details.

The temporal reference has in many cases changed direction, from pointing backward to forward. Now corporations are increasingly trying to present themselves as responsible for the future. A turn towards more responsible business practices can of course be seen as both desirable and advisable. A problem, however, is that much of the documentation of these responsible perspectives and achievements are presented in an increasingly ephemeral way; primarily for the eyes of the present onlooker who is expected soon to forget when their attention is directed towards something new.

This results in a tendency towards the faster but with shorter availability periods online when showing a responsibility for the future - in a shift from yesterday's foray into the past to today's volatile promises of a future. Pictorials are thus presented in a transposed grammatical order (antimetabole): from portraying the present for the future in printed documents to online envisioning the future for the present. Consequently, what has been a 
matter of portraying important achievements to posterity has increasingly become a matter of appearing for viewers today as responsible for the future.

The catchy phrases in the three pictorial examples evoke the image of corporations that are forward-looking and anticipatory of future outcomes. Still, at any one time, there may be a multitude of competing discourses upon which individuals and groups organize and define their situations and relationships. A way of understanding these verbal and visual discourses is through an analysis of the use of scopic regimes that directs attention towards a discourse to produce the behavior and belief of the group or the onlooker. Instead of only mimetically showing, a plotted story (diegesis) is directed by the scopic regime, at which someone deliberately has foregrounded and backgrounded certain visual attributes with temporal significance.

Scopic regimes in online corporate communications provide members and audiences with a visual orientation towards the desirable in the forefront and toning down the attention on the less favorable aspects. Such editing will of necessity be inclusive, including not only corporate "language" but also visual elements, practices, and ceremonies - for example, annual corporate events and other forms of recurrent corporate rituals used for rhetorical effect and persuasion, internally and externally. Employing approachable images, evocative poetic pictorials rather than prosaic content only, plays an increasingly important role in contemporary corporate communications, not least when presenting forward-looking statements.

Just like any communication, pictorial communication is about clarifying and reinforcing the message while leaving some parts obscured or hidden. What remains in obscurity is prior information from previous years, as the viewer is not expected to keep track of past years' promises. Instead short-time messages of sustainability are promoted. Comparability across years and follow ups may give way to promising new messages today about tomorrow's opportunities. Scopic regimes exert influence over cognitive, emotional, and aesthetic experiences, and especially in the context of a world that is increasingly mediated by pictorials, and which is therefore an increasingly "theatricalized and staged" (cf. Boorstin, 1961). The scene presented becomes "theatricalized" where actors "perform" for a particular "audience" in order to accomplish certain rhetorical tasks. Clearly, a specific doctrinal perspective is imposed upon corporate presentations. This is because online channels, as all media, carry with them certain assertions and beliefs (as well as platitudes) that become central components of any argument made through the use of that channel. In a constant flow of promising online messages in a scale never seen before, what 
is the lasting impression besides finding that it is easily accessible and easy to digest?

The attachment of symbolic meaning into pictorial scenes can be seen as an inculcation of a desired image of corporate behavior. Pictorial representation influences an audience's view of the world. Recurrent presentations "show us what we already know," reinforcing acceptance through the use of important virtuous symbolic configurations such as being energetic and executive but at the same time caring for coming generations. Scopic regimes can thus be seen as a lens or filter that utilizes pictorials in codification of beliefs, practices, taught principles, and dynamic positions. The pictorials together with their accompanying captions intensify and direct the message, when, for example, in picture 1, BMW in their 2012 "Sustainable value report" is exhibiting an electric scooter to be launched in 2014; the message of Ericsson's top executive conversation in picture 2 is directed by the confident caption: The connected society takes shape; and in picture 3, where the allegorical depiction of time and temporality is supported by the assertive (but somewhat tautological): Sustainable for the future. Even those who quickly scroll past are likely to be caught by such pictorials; they are immediate and instantly conveying messages. Representation is unavoidably selective at which recurrent foregrounding of "progress" in corporate pictorials advances a view toward the future.

Consequently, pictorials in contemporary corporate communications are frequently imbued with forward-looking temporal references to progress and development. And yet, at the same time, the transience of the online pictorials suggests that at least some of what is taken for granted right now, as being important documents of betterment is more volatile and ephemeral than ever before. This conclusion is perhaps not very remarkable or surprising per se. Similar situations can be found, for example, in the occasional short-termism among investors in long-term pension funds - or for that matter in the preservation of text, images, and sound produced and stored on less durable digital media. The question of how pictorials are used in corporate communications is nevertheless important and so is the question of what messages these pictorials convey, for instance about time and temporality.

Views that corporate communications are dominated by positive representations that bring out mainly male ideals of progress and strength are not new. Nor is it particularly surprising that online communication is fragmented and fast-paced. However, what is less emphasized is that online corporate messages of responsibility for the future are expected to have a short-online presence. Remembrance and return to a previous message is not expected. Instead, a stream of new responsibility messages replaces the previous ones, which means that presence and immediacy 
goes hand-in-hand with absence and forgetfulness (cf. Adam and Groves, 2007). Not only is there a flow of pictorials with salient temporal features of forward-looking scopic regimes at play, but the regime of temporality also include the changeable and flexible online document itself.

\section{Closing the stage}

There are recurring motifs in the use of pictorials in corporate communications, which construct identities and relations in the domain as well as overall systems of knowledge dissemination practices. Desirable words and images are beguiling, alluring, and recalcitrant, and their meaning are quite often in the eye of the beholder. Online pictorial communication ostensibly tries to be pleasing and intelligible in timely attempts to create appealing images. Corporate action depictions with partially blurred contours, decisive moment depictions, and symbolic depictions of temporality, all aims to convey an impression of progress and responsibility. The scopic attention is directed towards the promising future. The responsible and forwardlooking is foregrounded in such online corporate communications but is soon replaced by new and updated promises about the future. What once was about to present to posterity what was accomplished is now replaced with a focus on the responsibility for the future presented to today's inpatient spectators. Corporate undertakings must be presented understandably, preferably with pictorials, or its merits are not acknowledged. Timeliness has always played a major role in determining newsworthiness when reports have been presented, but there is nevertheless a shift in perspective towards increasingly fast-paced reporting on long-term commitments and responsibilities. Online reporting does not mean that issues of statements of accounts disappear, but it is undoubtedly easier to pay attention to today's online promises for the future than to follow-up last year's commitments - and the immediacy of pictorials in online culture is of central importance in this setting.

Corporations are increasingly directing their online communication not only towards experts and specialists but also to the general public. Not surprisingly, the messages are trying to convey a favorable image of the organization. This communication is increasingly visual, with not only stills but also video clips. When information becomes more immediate and targeted at the general public, there is also a risk that messages will be oversimplified and accepted all too uncritically. We are overwhelmed by pictorials that create unrealistic and often deceptive expectations of, for instance, corporate responsibility. This does not mean that all presentations are misleading, but we should not too readily accept the image conveyed. In a visual culture, the importance of interpreting nonverbal cues has become 
an increasing concern in recent years. Therefore, we must also pay attention to how various actors take part in and influence media and policy agendas through pictorial presentations.

Scopic regimes play a role in corporate communications, both in terms of foregrounding promising motifs and backgrounding less desirable aspects, but also in terms of the (ephemeral) online context where the pictorials are supposed to be seen and "consumed" by the impatient onlooker. Such visual narratives are thus far from the historical portraits' arranged quest for eternity. Progress used to be presented and preserved in print, but nowadays progress is promised in passing online portrayals.

\section{Conflict of interest}

None declared.

\section{Funding}

This research received no specific grant from any funding agency in the public, commercial, or not-for-profit sectors.

\section{References}

Adam B and Groves C (2007) Future Matters. Action, Knowledge, Ethics. Supplements to the Study of Time. Volume 3. Leiden: Brill.

Addison N (2003) Iconoscepticism: The value of images in education. In: Addison N and Burgess L (eds) Issues in Art and Design in Teaching. London: Routledge, pp. 122-133.

Alvesson M (1990) Organization: From substance to images? Organization Studies 11(3): 373-394.

Argenti PA (2006) How technology has influenced the field of corporate communication. Journal of Business and Technical Communication 20(3): 357-370.

Babe RE (2004) Innis, environment and new media. In: Moll M and Regan L (eds) Shade Seeking Convergence in Policy and Practice: Communications in the Public Interest, Vol. 2. Ottawa: Canadian Centre for Policy Alternatives, pp. 383-412.

Barthes R (1961/1977) The photographic message. In: Heath S (ed., trans.) Image, Music, Text. New York: Hill \& Wang, pp. 15-31.

Barthes R (1981) Camera Lucida. New York: Hill and Wang.

Bartram R (2004) Visuality, dromology and time compression - Paul Virilio's new occulacentrism. Time \& Society 13(2-3): 285-300.

Bell E and Davison J (2013) Visual management studies: Empirical and theoretical approaches. International Journal of Management Reviews 15(2): $167-184$.

Bergson H (1911/2007) Creative Evolution. New York: Cosimo.

Böhn A (2005) Memory, musealization and alternative history in Michael Kleeberg's novel Ein Garten im Norden and Wolfgang Becker's film Goodbye 
Lenin!. In: Arnold-de Simine S (ed.) Memory Traces: 1989 and the Question of German Culture Identity. Frankfurt: Peter Lang, pp. 245-260.

Böhn A (2007) Nostalgia of the media/in the media. In: Nöth W and Bishara N (eds) Self-Reference in the Media. Berlin: Walther de Gruyter, pp. 143-154.

Boorstin DJ (1961) The Image: A Guide to Pseudo-Events in America. New York: Vintage Books, 1992.

Breitbarth T, Insch A and Harris P (2010) Pictures at an exhibition revisited: Reflections on a typology of images used in the construction of corporate social responsibility and sustainability in non-financial corporate reporting. Journal of Public Affairs 10(4): 238-257.

Cartier-Bresson H (1952) Images à la sauvette [The Decisive Moment]. Paris: Editions Verve.

Castells M (1996) The Rise of the Network Society. The Information Age: Economy, Society and Culture, Vol. 1. Oxford: Blackwell.

Currie G (1995) Image and Mind: Film, Philosophy and Cognitive Science. Cambridge: Cambridge University Press.

Curtis N (ed.) (2010) The Pictorial Turn. London: Routledge.

Davison J (2007a) Rhetoric, repetition, reporting and the 'dot.com' era: Words, pictures, intangibles. Accounting, Auditing \& Accountability Journal 21(21): 791-826.

Davison J (2007b) Photographs and accountability: Cracking the codes of an NGO. Accounting, Auditing \& Accountability Journal 20(1): 133-158.

Davison J (2009a) Icon, iconography, iconology: Visual branding, banking and the case of the bowler hat. Accounting, Auditing \& Accountability Journal 22(6): 883-906.

Davison J (2009b) [In]visible [in]tangibles: Visual portraits of the business elite. Accounting, Organizations \& Society 35(2): 165-183.

Davison J (2014) Visual rhetoric and the case of intellectual capital. Accounting, Organizations and Society 39(1): 20-37.

De Cock C and Rehn A (2006) Editorial. Creativity and Innovation Management 15(2): 123-126.

Edwards JR (1989) The History of Financial Accounting. London: Routledge.

Elleström L (2010) The modalities of media: A model for understanding intermedial relations. In: Elleström L (ed.) Media Borders, Multimodality and Intermediality. Basingstoke: Palgrave Macmillan, pp. 11-48.

Feldman A (1997) Violence and vision: The prosthetics, aesthetics of terror in Northern Ireland. Public Culture 10(1): 25-60.

Feldman A (2005) On the actuarial gaze: From 9/11 to Abu Ghraib. Cultural Studies 19(2): 203-226.

Gombrich EH (1964) Moment and movement in art. Journal of the Warburg and Courtauld Institutes 27: 293-306.

Goodman MB and Hirsch PB (2010) Corporate Communication: Strategic Adaptation for Global Practice. New York: Peter Lang Publishing.

Gregory D (2003) Emperors of the gaze: Photographic practices and productions of space in Egypt, 1839-1914. In: Schwartz JM and Ryan JR (eds) Picturing Place: Photography and the Geographical Imagination. London: IB Tauris, pp. 195-225. 
Harvey D (1990) The Condition of Postmodernity: An Enquiry into the Origins of Cultural Change. Cambridge, MA: Blackwell.

Innis H (1951) The Bias of Communication. Toronto: University of Toronto Press. Jay M (1988) Scopic regimes of modernity. In: Foster H (ed.) Vision and Visuality. Seattle: Bay Press, pp. 3-23.

Jay M (1993) Downcast Eyes: The Denigration of Vision in Twentieth-Century French Thought. Berkeley: University of California Press.

Kelly M (1998) Mimesis. In: Kelly M (ed.) The Encyclopedia of Aesthetics. Vol. 3. Oxford: Oxford University Press, p. 233.

Kress G and van Leeuwen T (2006) Reading Images. The Grammar of Visual Design. 2nd ed. London: Routledge.

Le Poidevin R (2007) The Images of Time: An Essay on Temporal Representation. Oxford: Oxford University Press.

Lester P (1991) Photojournalism: An Ethical Approach. Hillsdale: Erlbaum.

Linstead S and Höpfl H (eds) (2000) The Aesthetics of Organization. London: Sage.

Lübbe H (1990) Zeit-Verhältnisse. Über die veränderte Gegenwart von Zukunft und Vergangenheit. In: Zacharias W (ed.) Zeitphnomen Musealisierung. Das Verschwinden der Gegenwart und die Konstruktion der Erinnerung. Essen: Klartext-Verlag, pp. $40-50$.

Lucaites JL and Hariman R (2001) Visual rhetoric, photojournalism, and democratic public culture. Rhetoric Review 20(1/2): 37-42.

Luhmann N (1976) The future cannot begin: Temporal structures in modern society. Social Research 43(1): 130-152.

McKinstry S (1996) Designing the annual reports of Burton PLC from 1930 to 1994. Accounting, Organizations and Society 21(1): 89-111.

McLuhan M (1964/1994) Understanding Media: The Extensions of Man. Cambridge, MA: The MIT Press.

Marcum JW (2002) Beyond visual culture: The challenge of visual ecology. Libraries and the Academy 2(2): 189-206.

Massey D (1994) Space, Place and Gender. Cambridge: Polity Press.

Metz C (1981) The Imaginary Signifier: Psychoanalysis and the Cinema. Bloomington: Indiana University Press.

Metz C (1974/1991) Film Language: A Semiotics of the Cinema. Chicago: University of Chicago Press (first published in French).

Meyer R, Höllerer MA, Jancsary D, et al. (2013) The visual dimension in organizing, organization, and organizational research. Academy of Management Annals 7(1): 487-553.

Mignolo WD (2000) Local Histories/Global Designs: Coloniality, Subaltern Knowledges, and Border Thinking. Princeton: Princeton University Press.

Mitchell WJT (1984) The politics of genre: Space and time in Lessing's Laocoon. Representations 6(1): 98-115.

Mitchell WJT (1986) Iconology: Image, Text, Ideology. Chicago: University of Chicago Press. 
Mitchell WJT (1994) Picture Theory. Essays on Visual and Verbal Representation. Chicago: University of Chicago Press.

Moya Guijarro J and Pinar Sanz MJ (2008) Compositional, interpersonal and representational meanings in a children's narrative. A multimodal discourse analysis. Journal of Pragmatics 40(9): 1601-1619.

Norris C (2012) The success of failure. Accounting for the global growth of CCTV. In: Ball K, Haggerty K and Lyon D (eds) Routledge Handbook of Surveillance Studies. Milton Park: Routledge, pp. 251-258.

Nowotny H (1994) Time. The Modern and Postmodern Experience. Cambridge: Polity Press.

Panofsky E (1955) Meaning in the Visual Arts. Chicago: University of Chicago Press.

Parker RH (1990) Regulating British corporate financial reporting in the late nineteenth century. Accounting, Business \& Financial History 1(1): 51-71.

Pazzini KJ (1989) Tod im Museum. Über eine gewisse Nähe von Pädagogik, Museum und Tod. In: von Groppe $\mathrm{H}-\mathrm{H}$ and Jürgensen $\mathrm{F}$ (eds) Gegenstände der Fremdheit. Museale Grenzgänge. Marburg: Jonas Verlag, pp. 124-136.

Perlmutter DD (1997) Manufacturing visions of society and history in textbooks. Journal of Communication 47(3): 68-81.

Pietrzyk K (2012) Preserving digital narratives in an age of present-mindedness. Convergence: The International Journal of Research into New Media Technologies 18(2): 127-133.

Pink S (2006) Doing Visual Ethnography: Images, Media and Representation in Research. 2nd ed. London: Sage.

Preston AM, Wright C and Young JJ (1996) Imag(in)ing annual reports. Accounting, Organizations and Society 21(1): 113-137.

Rämö H (2011) Visualizing the phronetic organization: The case of photographs in CSR reports. Journal of Business Ethics 104(3): 371-387.

Ray JL and Smith AD (2012) Using photographs to research organizations: Evidence, considerations, and application in a field study. Organizational Research Methods 15(2): 288-315.

Rhodes C and Pullen A (2010) Editorial: Neophilia and organization. Culture and Organization 16(1): 1-6.

Rosteck T (1994) See It Now Confronts McCarthyism: Television Documentary and the Politics of Representation. Tuscaloosa: University of Alabama Press.

Rushkoff D (2013) Present Shock: When Everything Happens Now. New York: Current Hardcover/Penguin.

Schillmeier M (2008) Time-spaces of in/dependence and dis/ability. Time \& Society 17(2-3): 215-231.

Schnettler B and Raab J (2009) Interpretive visual analysis developments: State of the art and pending problems. Historical Social Research - Historische Sozialforschung 34(2): 265-295.

Seward Barry AM (1997) Visual Intelligence: Perception, Image, and Manipulation in Visual Communication. Albany: State University of New York Press. 
Smithsonian Institution (1998) Smithsonian Institution's Cooper-Hewitt Museum National Museum of Design. A Historical Review of Annual Report Design. Washington, DC: Smithsonian Institution.

Strati A (1997) Organization as hypertext: A metaphor from visual cultures. Culture and Organization 3(2): 307-324.

Styhre A (2009) The cinematic mode of organizing: Media and the problem of attention in organization theory. Information and Organization 19(1): 47-58.

Styhre A (2010) Visual Culture in Organizations: Theory and Cases. New York: Routledge.

Taussig M (1993) Mimesis and Alterity: A Particular History of the Senses. New York: Routledge.

Toffler A (1970) Future Shock. New York: Random House.

Urry J (2000) Sociology Beyond Societies: Mobilities for the Twenty-First Century. London: Routledge.

Virilio P (1991) The Aesthetics of Disappearance. New York: Semiotext(e).

Virilio P (1997) Open Sky. London: Verso.

Yates JA and Orlikowski WJ (1992) Genres of organizational communication: A structurational approach to studying communication and media. The Academy of Management Review 17(2): 299-326.

Yates JA and Orlikowski WJ (2002) Genre systems: Structuring interaction through communicative norms. The Journal of Business Communication 39(1): 13-35.

Yates JA and Orlikowski WJ (2007) The powerpoint presentation and its corollaries: How genres shape communicative action in organizations. In: Zachry M and Thralls C (eds) The Cultural Turn: Communicative Practices in Workplaces and the Professions. Amityville: Baywood, pp. 67-92. 


\section{Appendix I. Pictures}

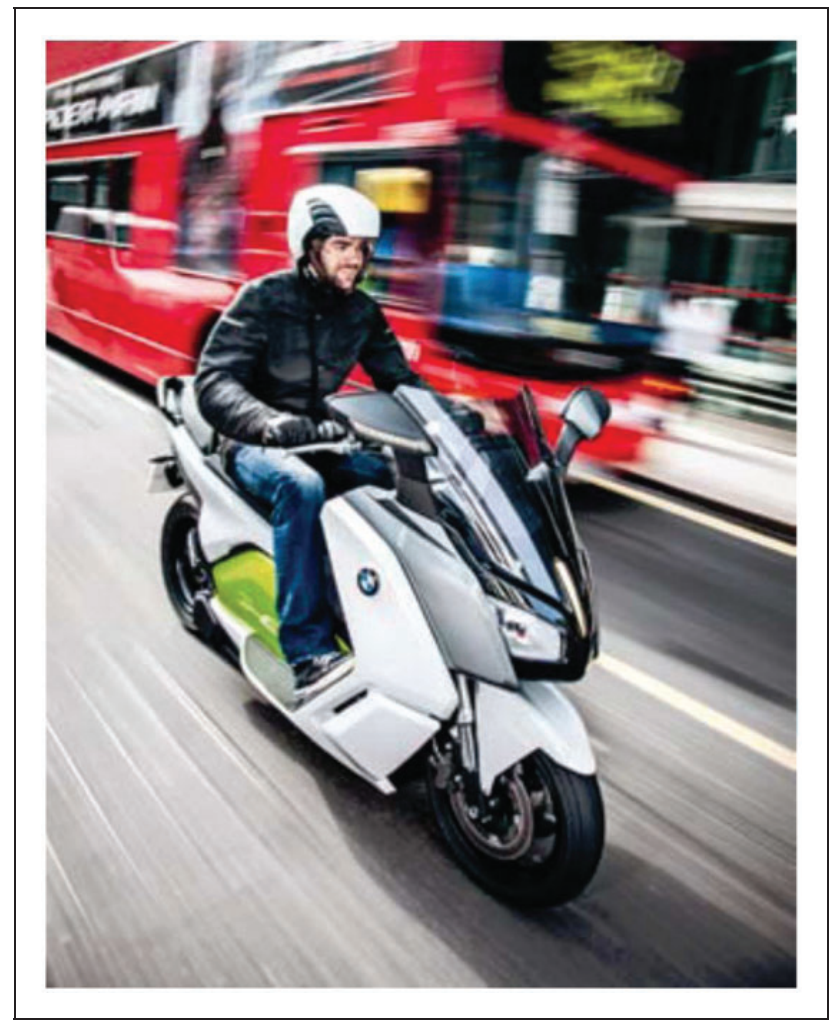

Picture I. On sale from 20I4-The new electric scooter from BMW. Source: BMW Group (2012: 39) Sustainable Value Report 2012. 


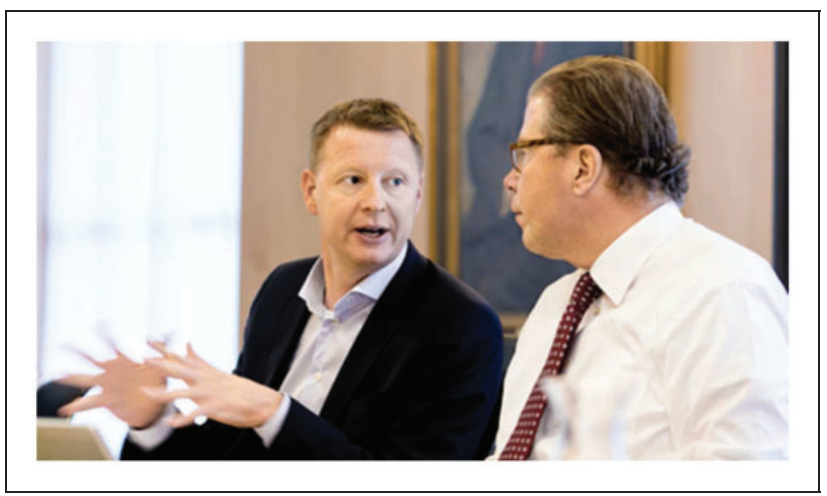

Picture 2. Hans Vestberg, CEO of Ericsson, vigorously talking to Leif Johansson, chairman of the board of Ericsson. A forward-looking and promising preamble above the picture says (in Swedish, excluded here): The connected society takes shape. Source: Ericsson 2012, http://www.ericsson.com/thecompany/investors/financial_reports/2012/ annual I $2 /$ sv/bolagsstyrning/styrelsen 


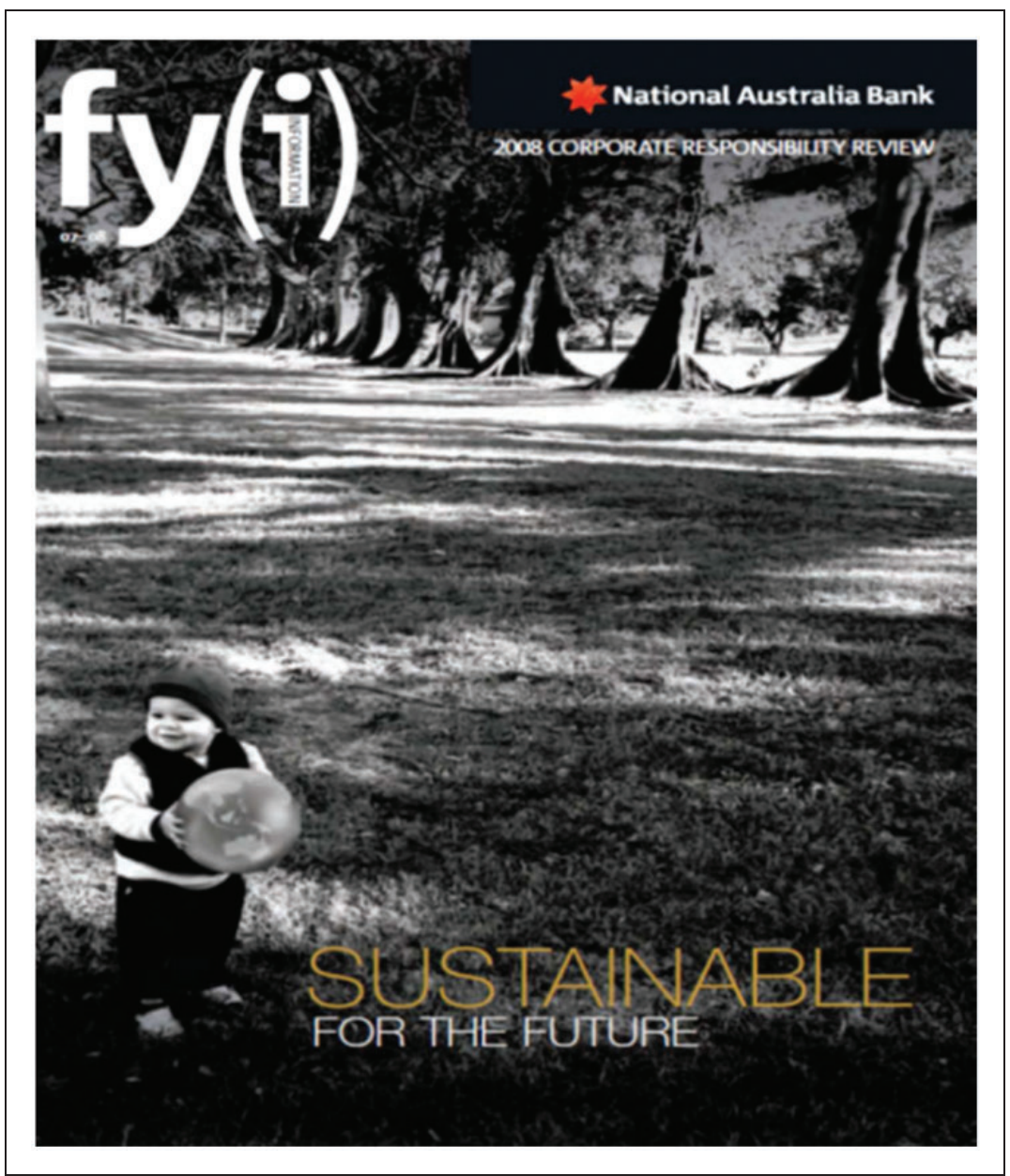

Picture 3. A young child with an inflatable globe in an ancient forest. Source: National Australia Bank, 2008 Corporate Responsibility Review. 